\title{
Arylboronic Acids Catalyzed Upgrade of Glucosamines for Deoxyfructosazine and Insights on Reaction Mechanism
}

\author{
Meifeng Wang†t, Gan Zhu†t, Yiqun Li*t, Liuqun $\mathrm{Gu}^{* \dagger}$ \\ $\dagger$ Department of Biomedical Engineering, Jinan University; \#601, Huangpu Avenue West, \\ Guangzhou, China \\ † Department of Chemistry, Jinan University; \#601, Huangpu Avenue West, Guangzhou, \\ China
}

\begin{abstract}
Chitin is the most abundant $\mathrm{N}$-containing polysaccharides in nature and D-glucosamine is one of most successful commercial monomer products in current market. Here we reported an arylboronic acids catalyzed upgrade of glucosamines in aqueous solution for deoxyfructosazine which is an important high-value compound in pharmaceutical and food industries, as well as a promising bio-based platform molecule for speciality chemicals and sustainable functional materials. Such direct integration of deoxyfructosazine into development of renewable chemicals/functional materials might be a practical way for utilization of chitin as a renewable nitrogen source. A mechanism focusing on catalytic cycle of arylboronic acid via a boron transfer was also proposed.
\end{abstract}

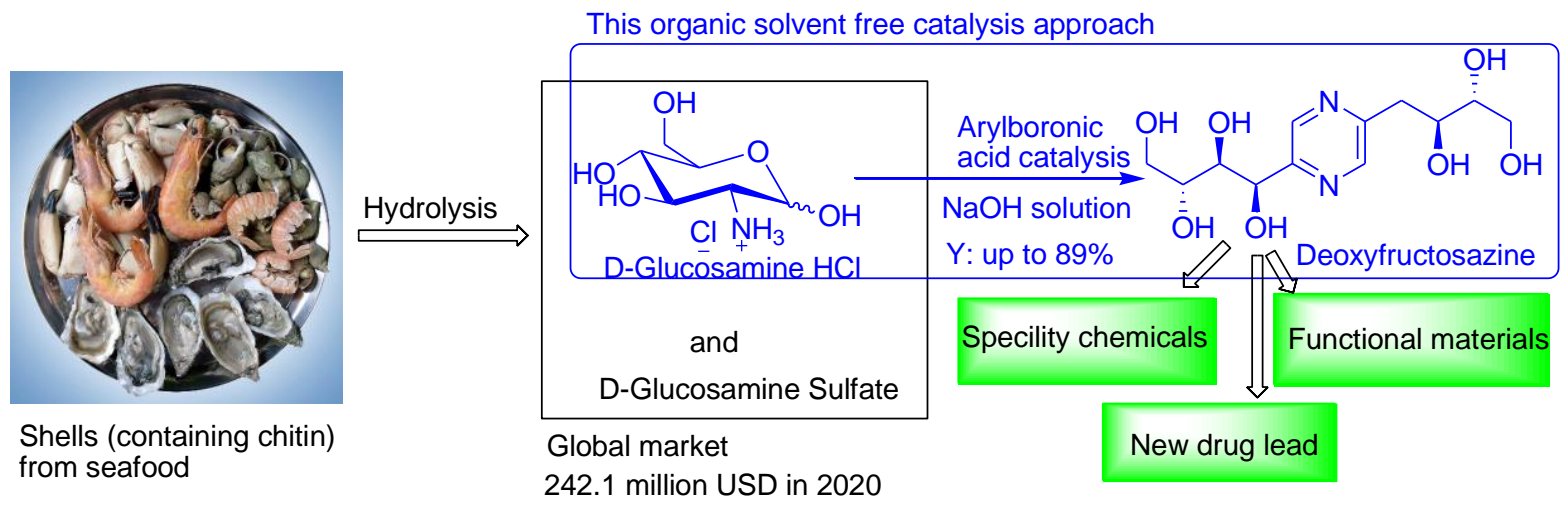

\section{Introduction}

Chitin is the second most abundant biopolymer in nature following cellulose, and the most abundant $\mathrm{N}$-containing polysaccharide excluding proteins. Because only a few natural amines are available and their importance as key intermediates in chemical industry, chitin is promising to be the largest renewable amine source in the future, contributing to decarbonization for sustainability. ${ }^{1,2}$ However, utilization of chitin or its deacetylation product chitosan is rather limited mainly because high purity of chitin is not accessible economically with current purification methods; in addition, structures of chitin are also not same from different sources, which led to more difficulty in followed modifications for derivatives. $3,4,5$ Such recalcitrant structure usually led to complex products in direct conversion of chitin into chemicals, and not surprisingly its hydrolysed monomer N-acetyl-D-glucosamine (NAG) was frequently used for preparation of bio-based chemicals such as 3-acetamidofuran, 3-acetamido- 
5-acetylfuran (3A5AF), acetamidoacetaldehyde, pyridine and so on. ${ }^{6}$ Very recently bio-based cyclic and short-chained aliphatic amines were also produced from NAG by selectively removing the oxygenated group over $\mathrm{Ru} / \mathrm{C}$, and an acid co-catalyst $\mathrm{H}_{3} \mathrm{PO}_{4}$ is proved to be vital for retaining the amino group in NAG by protonation. ${ }^{7}$ Although significant progress was achieved in reported literatures, new catalytic systems to synthesize high-value-added Ncontaining chemicals from NAG or deacetylated monomer D-glucosamine ( $\mathrm{HCl}$ salt or sulfate salt) are still highly desired for better nitrogen cycle. Here we reported an arylboronic acids catalyzed dimerization of glucosamine forming deoxyfructosazine (Scheme 1); the reaction could be completed in a few hours and yield of sole product was excellent. Deoxyfructosazine is widely used in food industry and also showed therapeutic potential in treatments of diabetes ${ }^{8}$ and immunological diseases ${ }^{9}$ as well as DNA strand breakage activity ${ }^{10}$; its unique structure containing pyrazine moiety ${ }^{11}$ and multiple hydroxyls ${ }^{12}$ make it very promising platform molecule for speciality chemicals and new smart materials.

Scheme 1. A "drop-in" upgrade of D-glucosamine with arylboronic acid catalysis on current utilization of chitin.

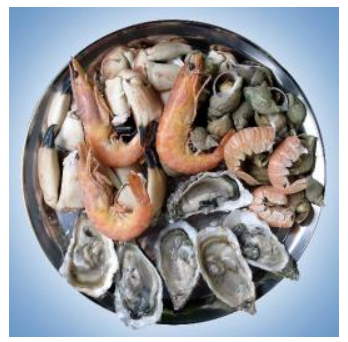

Shells (containing chitin) from seafood

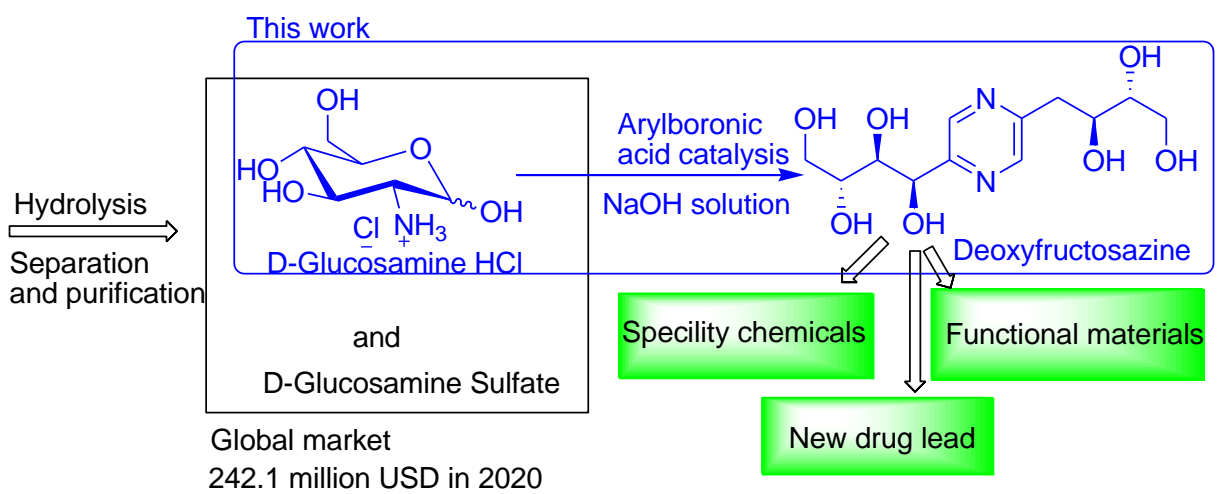

A good conversion of D-glucosamine hydrochloride to deoxyfructosazine in the presence of excess amount (2.5 to 5 equivalents) of phenylboronic acid and excess amount of $\mathrm{NaOH}$ in water was initially reported by J. A. Peters $e t . a l^{13}$, which was a cleaner transformation and a significant progress based on pioneer works in alkali hydroxide solution only ${ }^{10}$ or pyridine solution only ${ }^{14}$. Further optimization on this conversion with phenylboronic acid as a promoter $^{15}$ or boric acid as an additive with 1-ethyl-3-methylimidazolium acetate $\left(\left[\mathrm{C}_{2} \mathrm{C}_{1} \mathrm{Im}\right][\mathrm{OAc}]\right)$ as a catalyst ${ }^{16}$ or in deep eutectic solvents ${ }^{17}$ was also reported, however yield of deoxyfructosazine was generally low to moderate although more clues were achieved in mechanism investigation ${ }^{16,17}$. In these literatures (Scheme 1), excess amount of phenylboronic acid or boric acid is still a must for achieving a good yield of deoxyfructosazine. It was generally proposed that phenylboronic acid or boric acid masked diols on glucosamine and then subsequent dimerization reaction occurred.

Arylboronic acids as organocatalysts were widely used in various organic transformations ${ }^{18-}$ ${ }^{20}$ for pharmaceutical intermediates, forming reversible covalent bond with hydroxyl groups of carboxylic acids or alcohols. However, their application as catalysts in selective transformations for glycosides was less explored and very few progress was reported. D. Takahashi and K. Toshima found aromatic boronic acids could catalyze glycosylation of both protected $^{21}$ and unproctected ${ }^{22}$ sugar acceptors with epoxide ring in a regioselective manner via $S_{N}$ i-type mechanism in the presence of water. Site-selective sulfonation unprotected 
monosaccharides catalyzed by chiral benzazaborole in $\mathrm{MeCN}^{23}$ and site-selective acylation catalyzed by Shimada's boronic acid catalyst in dioxane ${ }^{24}$ were also reported very recently. Encouraged by this progress and our previous knowledge ${ }^{25}$ on arylboronic acid catalyzed amide formation from carboxylic acids and amines, we envisaged that arylboronic acids might be possible to act as a catalyst instead of a reagent in upgrade of glucosamines for deoxyfructosazine under a suitable condition.

\section{Experimental Section}

\section{General procedure and yield calculation}

\subsection{General procedure for Table 1.}

D-Glucosamine hydrogen chloride (107.8 mg, $0.50 \mathrm{mmol})$ and $\mathrm{PhB}(\mathrm{OH})_{2}(24.4 \mathrm{mg}, 0.20 \mathrm{mmol})$ were added into different volumes of aqueous $\mathrm{NaOH}(0.1 \mathrm{~N})$ solution; the reaction mixture was stirred for $36 \mathrm{hrs}$ at room temperature. Then the reaction mixture was acidified $(\mathrm{pH}$ value $=1$ 3 ) by dropwise addition of $2 \mathrm{~N} \mathrm{HCl}$ aqueous solution, and subsequently the mixture was stirred for another 30 mins. After then, $1 \mathrm{~mL}$ of the reaction mixture was taken out to another flask mixing with ethanol for fast evaporation under reduced pressure at $33^{\circ} \mathrm{C}$. Further drying in vaccum gave a crude product for ${ }^{1} \mathrm{H}$ NMR to determine a yield (In most samples, ethanol was difficult to be fully removed due to strong hydrogen bonding with DOF, however, its existence didn't affect yield calculation; see Ref 26).

\subsection{General procedure for Table 2.}

D-Glucosamine hydrogen chloride $(107.8 \mathrm{mg}, 0.50 \mathrm{mmol})$ and $\mathrm{ArB}(\mathrm{OH})_{2}(0.20 \mathrm{mmol})$ were added into aqueous $\mathrm{NaOH}(0.1 \mathrm{~N}, 6.5 \mathrm{~mL})$ solution and the reaction mixture was stirred for 36 $\mathrm{hrs}$ at room temperature; then the reaction mixture was acidified ( $\mathrm{pH}$ value $=1-3$ ) by dropwise addition of $2 \mathrm{~N} \mathrm{HCl}$ aqueous solution, and subsequently the mixture was stirred for another 30 mins. After then, $1 \mathrm{~mL}$ of the reaction mixture was taken out to another flask mixing with ethanol for fast evaporation under reduced pressure at $33^{\circ} \mathrm{C}$. Further drying in vaccum gave a crude product for ${ }^{1} \mathrm{H}$ NMR to determine a yield.

\subsection{Procedure for Table 3.}

D-Glucosamine hydrogen chloride $(107.8 \mathrm{mg}, 0.50 \mathrm{mmol})$ and $\mathrm{ArB}(\mathrm{OH})_{2}(24.4 \mathrm{mg}, 0.20 \mathrm{mmol})$ were added into $\mathrm{NaOH}(0.1 \mathrm{~N}, 6.5 \mathrm{~mL})$ aqueous solution and the reaction mixture was stirred for $6 \mathrm{hrs}$ or $12 \mathrm{hrs}$ at $40^{\circ} \mathrm{C}$ or $60^{\circ} \mathrm{C}$. Then the reaction mixture was acidified ( $\mathrm{pH}$ value $=1-3$ ) by dropwise addition of $2 \mathrm{~N} \mathrm{HCl}$ aqueous solution, and subsequently the mixture was stirred for another 30 mins. After then, $1 \mathrm{~mL}$ of the reaction mixture was taken out to another flask mixing with ethanol for fast evaporation under reduced pressure at $33^{\circ} \mathrm{C}$. Further drying in vaccum gave a crude product for ${ }^{1} \mathrm{H}$ NMR to determine a yield.

\subsection{Method to determine yields based on ${ }^{1} \mathrm{H}$ NMR for all tables.}

Integration of unique peak of DOF product at $\delta 5.20$ and integration of unique peak of Dglucosamine at $\delta 3.50$ (similar protons of both alpha-form and beta-form are at the same position) were used to determine yield because both of the peaks were clearly or mostly separated from neighbour peaks (very small overlapped area in some entries). An analysis of sample spectra see supporting information.

\subsection{Procedure for quantitative ${ }^{1} \mathrm{H}$ NMR analysis for entries 7 and 8 in Table 3.}


D-Glucosamine hydrogen chloride (107.8 $\mathrm{mg}, 0.50 \mathrm{mmol})$ and $\mathrm{PhB}(\mathrm{OH})_{2}$ or 3$\mathrm{NH}_{2} \mathrm{C}_{6} \mathrm{H}_{4} \mathrm{~B}(\mathrm{OH})_{2}(0.20 \mathrm{mmol})$ were added into a solution of $\mathrm{NaOH}(0.1 \mathrm{~N}, 6.5 \mathrm{~mL})$, the mixture was stirred for 6 hours at $60^{\circ} \mathrm{C}$. Then the reaction mixture was acidified ( $\mathrm{pH}$ value $=1-3$ ) by dropwise addition of $2 \mathrm{~N} \mathrm{HCl}$, and subsequently the mixture was stirred for another 30 mins. After acidification respectively, the reaction mixture was mixed with ethanol and was evaporated to dryness under reduced pressure at $33^{\circ} \mathrm{C}$. Removal of residual solvent in vaccum gave a crude product. Their weights were $166.3 \mathrm{mg}$ and $158.4 \mathrm{mg}$, respectively. The yield of DOF was quantitatively analysed by ${ }^{1} \mathrm{H}$ NMR using pyrazine as an internal standard substance: the crude product was mixed with pyrazine $(0.05 \mathrm{mmol})$, and $\mathrm{D}_{2} \mathrm{O}(1 \mathrm{~mL})$, after mixing thoroughly, partial mixture was transferred to an NMR tube for ${ }^{1} \mathrm{H}$ NMR measurement.

IntDOF: Integration of unique peak of DOF product at $\delta 5.20(1 \mathrm{H})$;

IntPy: integration of pyrazine peak at $\delta 8.60(4 \mathrm{H})$;

Mol of DOF $(2 \times$ D-Glucosamine $)=($ IntDOF $/$ IntPy $) \times 4 \times 0.05 \mathrm{mmol}$;

DOF yield regarding on D-Glucosamine hydrogen chloride was calculated as:

$$
\text { Yield }=2 \times \frac{(\text { IntDOF } / \text { IntPy }) \times 4 \times 0.05 \mathrm{mmol}}{0.5 \mathrm{mmol}} \times 100 \%
$$

(Integrated ${ }^{1} \mathrm{H}$ NMR Spectra sees supporting information).

\section{Results and discussion}

Because arylboronic acids can be handled in air without special precautions and mostly are chemically stable for long periods of time, we revisited an experiment in literature ${ }^{13}$ with phenylboronic acid as a sole promoter (Glucosamine hydrogen chloride to phenylboronic acid $=1: 1$ ), and surprisingly both free deoxyfructosazine and its boronic acid ester form were both observed in crude ${ }^{1} \mathrm{H}$ NMR (Figure 1) ${ }^{26}$. From the spectra, clear two more small peaks $(\delta=$ $8.63,8.45)$ appeared near to two big peaks $(\delta=8.67,8.48)$, and likely they represented two types of pyrazine moieties; after acidification ( $\mathrm{HCl}$ solution), two small peaks disappeared along with some peaks in aromatic range indicated that the two small peaks likely belong to phenylboronic acid protected deoxyfructosazine. And most of deoxyfructosazine (DOF) were actually in free form under our revisited condition. Encouraged by this finding, we envisaged that a catalytic cycle might be realized if boronic acid could transfer from protected deoxyfructosazine to a free glucosamine directly or be released to be a free acid via a dissociation as proposed in Scheme 2 by tuning reaction conditions. Arylboronic acid might react with one molecular of D-glucosamine forming ester intermediate $\mathbf{3}$, then activated ester intermediate 3 further cyclized themselves or with another one molecular of D-glucosamine forming boronic acid protected DOF 4 . Subsequently a boron transfer might occur between product $\mathbf{4}$ and D-glucosamine regenerating ester intermediate $\mathbf{3}$ for next catalytic cycle or release free arylboronic acid. After all or most of D-glucosamines are consumed, a mixture of protected product $\mathbf{4}$ and free deoxyfructosazine will be achieved at the end.

Figure 1. Crude ${ }^{1} \mathrm{H}$ NMR spectra for revisited reaction (phenylboronic acid to glucosamine hydrochloride is $1: 1)$. 


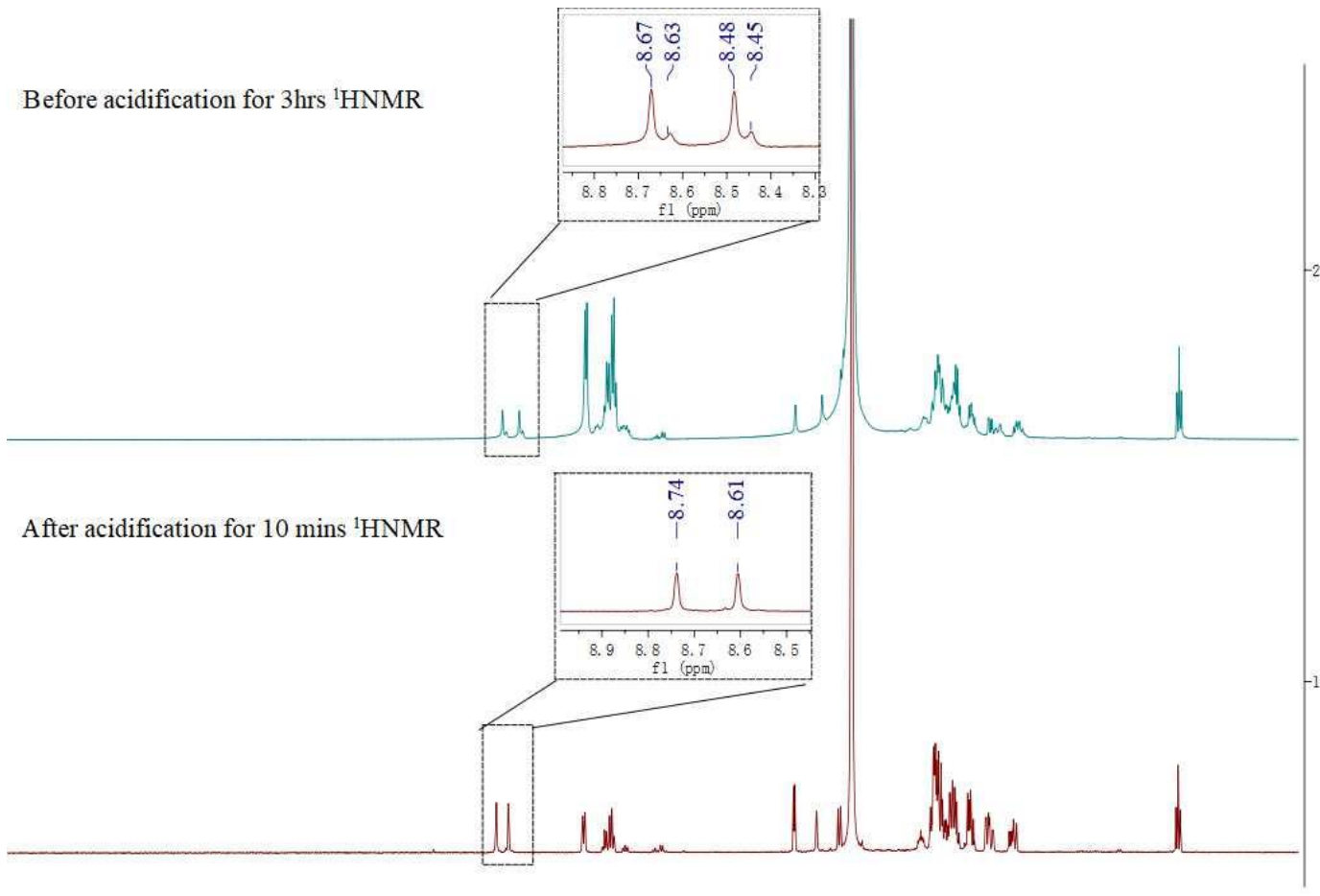

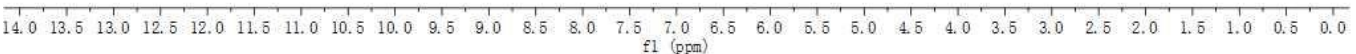

Scheme 2. Proposed catalytic cycle via boron transfer.

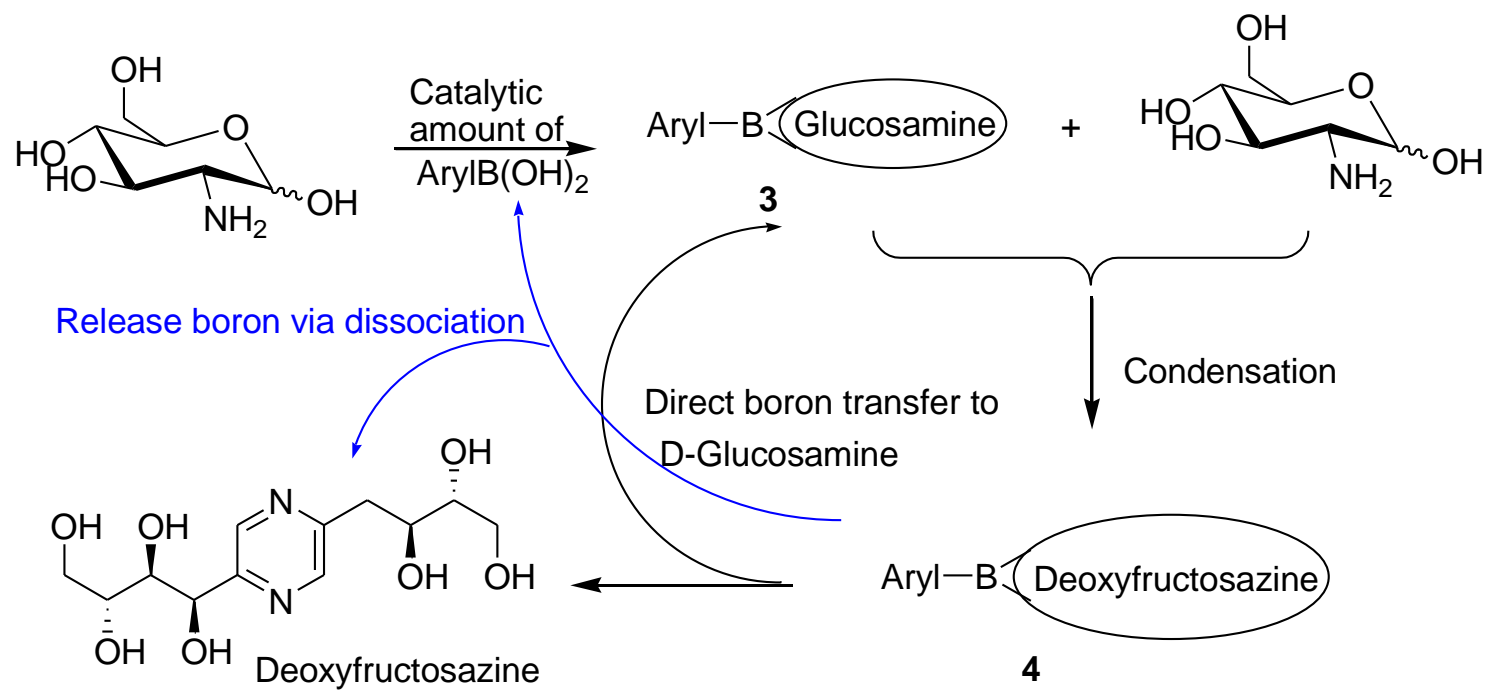

Based on this hypothesis, we initially investigated effect of base on deoxyfructosazine formation with $40 \mathrm{~mol} \%$ phenylboronic acid as a catalyst in different volume of $0.1 \mathrm{~N} \mathrm{NaOH}$ solution for $36 \mathrm{hrs}$ at room temperature. Because at least 1 equiv. base was necessary in order to neutralize hydrogen chloride within the starting material D-glucosamine hydrogen chloride, we selected a range of 1.0 to 1.5 equiv. of $\mathrm{NaOH}$ (equivalent to $\mathrm{D}$-glucosamine hydrogen chloride) for the parallel study (Table 1). The increase of base till 1.3 equiv. led to increase on deoxyfructosazine yield (Entries 1 - 4, Table 1). Yield of deoxyfructosazine decreased slightly with an increase of base use over 1.3 equiv. (Entries 4 - 6, Table 1) and obvious amount of byproduct fructosazine appeared, probably because of the presence of more base accelerated further oxidization of deoxyfructosazine to fructosazine. The best yield $(68 \%)$ of 
deoxyfructosazine was achieved in the presence of 1.3 equiv. $\mathrm{NaOH}$ (Entry 4, Table 1) although the difference was not significant within the range (1.1 to 1.5$)$. The yield was much over $40 \%$ (Usage of phenylboronic acid), which indicated the catalytic cycle indeed occurred as expected.

Table 1. Investigation on Base Effect.

2<smiles>O=[N+]([O-])C1C(O)COC(O)C(O)C1O</smiles>
$\underset{0.1 \mathrm{~N} \mathrm{NaOH}, \mathrm{rt}, 36 \mathrm{~h}}{\stackrel{40 \mathrm{PhB}(\mathrm{OH})_{2}}{\longrightarrow}}$

D-Glucosamine hydrogen chloride<smiles>OC[C@@H](O)C(O)c1cnc(C[C@H](O)[C@H](O)CO)cn1</smiles>

Deoxyfructosazine

\begin{tabular}{ccc}
\hline Entry & NaOH(equiv.) & ${\text { Yield }[\%]^{[\mathbf{a}]}}^{\mathbf{1}}$ \\
$\mathbf{2}$ & 1.0 & 56 \\
$\mathbf{3}$ & 1.1 & 64 \\
$\mathbf{4}$ & 1.2 & 65 \\
$\mathbf{5}$ & 1.3 & 68 \\
$\mathbf{6}$ & 1.4 & 59 \\
\hline
\end{tabular}

[a] Determined by crude ${ }^{1} \mathrm{H}$ NMR.

Next in the presence of 1.3 equiv. $\mathrm{NaOH}(0.1 \mathrm{~N})$ aqueous solution, we screened a few arylboronic acids commercially available in order to investigate effect of functional groups on aromatic moiety (Table 2). In the absence of any boronic acid, the reaction gave no desired product deoxyfructosazine and only small amount of fructosazine was observed (Entry 1, Table 2), which proved the catalysis role of arylboronic acid. Electron-donating groups of $\mathrm{OMe}$ and $\mathrm{O}^{\mathrm{P} P}$ on arylboronic acids led to an obvious drop on reaction yield (Entries 2 - 4, Table 2). Electron-deficient groups of $\mathrm{CF}_{3}$ on 2-position and penta-fluoridation also had negative effect on catalytic efficiency (Entries 5 and 7, Table 2). Meanwhile comparable yield was observed surprisingly when 3,5-di(trifluoromethyl)arylboronic acid or 2-fluoroarylboronic acid was employed as a catalyst (Entries 6 and 8, Table 2). It was concluded that inductive electronic effect had influence on reaction yield, but definitely was not the only dominated factor. A favoured fluoride bonding (H-F bonding, F-B bonding) also likely played an important role. Subsequently some arylboronic acids with interactive groups on aromatic moiety were also evaluated (Entries 9 - 12, Table 2) in order to investigate potential hydrogen bonding assistant effect. The existence of carboxylic acid group on 3-position or hydroxyl group on 4-position both slowed down the self-condensation reaction rate and lower yields of deoxyfructosazine were observed (Entries 9 and 10, Table 2). To our delight, amino group on 3-position did benefit the conversion and $76 \%$ yield of deoxyfructosazine was obtained with which as a catalyst under the same conditions (Entry 11, Table 2); pyridyl boronic acid delivered a similar 
good catalytic efficiency (Y: 78\%) (Entry 12, Table 2) although the mechanism in detail on how pyridyl group and amino group assist the self-condensation is still unknown.

Table 2. Screening Catalysts of Aryl Boronic Acids ${ }^{[a]}$

2
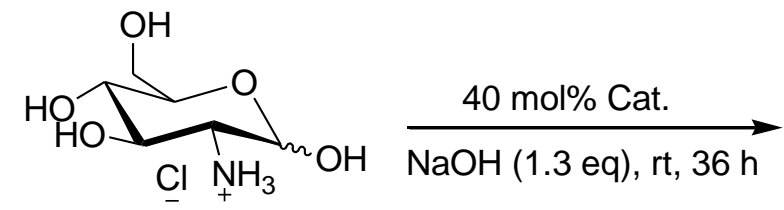

D-Glucosamine hydrogen chloride<smiles></smiles>

\begin{tabular}{lll}
\hline Entry & $\begin{array}{l}\text { Cat. } \\
{\left[\text { ArB }(\mathrm{OH})_{2}\right]}\end{array}$ & Yield $^{[\mathrm{b}]}$ \\
\hline 1 & None & $0^{[\mathrm{c}]}$ \\
2 & Phenyl & 68 \\
3 & $2,5-$ & 60 \\
& $(\mathrm{MeO})_{2} \mathrm{C}_{6} \mathrm{H}_{3}$ & \\
4 & $4-{ }^{-} \mathrm{PrOC}_{6} \mathrm{H}_{4}$ & 57 \\
5 & $2-\mathrm{CF}_{3} \mathrm{C}_{6} \mathrm{H}_{4}$ & 46 \\
6 & $3,5-\left(\mathrm{CF}_{3}\right)_{2} \mathrm{C}_{6} \mathrm{H}_{3}$ & 69 \\
7 & $2,3,4,5,6-\mathrm{F}_{5} \mathrm{C}_{6}$ & 39 \\
8 & $2-\mathrm{FC}_{6} \mathrm{H}_{4}$ & 71 \\
9 & $3-\mathrm{HOOCC}_{6} \mathrm{H}_{4}$ & 59 \\
10 & $4-\mathrm{HOCH}_{2} \mathrm{C}_{6} \mathrm{H}_{4}$ & 69 \\
11 & $3-\mathrm{NH}_{2} \mathrm{C}_{6} \mathrm{H}_{4}$ & 76 \\
12 & $4-\mathrm{Pyridyl}$ & 78
\end{tabular}

[a] Reaction conditions: D-Glucosamine hydrochloride $(0.5 \mathrm{mmol})$ and $\operatorname{ArB}(\mathrm{OH})_{2}$ $(0.2 \mathrm{mmol})$ were stirred in $\mathrm{NaOH}$ solution $(6.5 \mathrm{~mL} ; 0.1 \mathrm{~N})$ for $36 \mathrm{~h}$ at room temperature.

[b] Determined by crude ${ }^{1} \mathrm{H}$ NMR.

[c] Contains trace fructosazine.

Since catalyst optimization indicated that catalyst $\mathbf{1}$ and $\mathbf{2}$ showed better activity (Table $\mathbf{2}$ ), we further optimized reaction temperature in the presence of the two best catalysts as well as phenylboronic acid (Table 3). Initially a parallel study of self-condensation reactions with the three catalysts respectively (Entries 1 - 3, Table 3) was performed at $40^{\circ} \mathrm{C}$ for 6 hours (Optimization of catalyst loading of $\mathrm{PhB}(\mathrm{OH})_{2}$ at $40^{\circ} \mathrm{C}$ sees STable 1 in supporting information); and yields of deoxyfructosazine were comparable to these achieved at room temperature for 36 hours (Entries 1, 10 and 11, Table 2). Prolonged reaction time to 12 hours only slightly improved yields for all reactions with three catalysts (Entries 4 - 6, Table 3). A further increase of temperature to $60^{\circ} \mathrm{C}$ had remarkable impact on reaction efficiency and excellent yields of deoxyfructosazine (Entries 7 - 9, Table 3) were achieved for all three parallel reactions in 6 hours. To our excitement, the reactions still kept clean at $60^{\circ} \mathrm{C}$; no fructosazine or other side products from decomposition of D-glucosamine was observed. Even though pyridylboronic acid catalyst 2 still showed the highest activity (Y: 89\%), yield difference with either of catalyst 1 (Y: 86\%) and phenylboronic acid (Y: 85\%) became very 
narrow. A further optimization on base use at $40^{\circ} \mathrm{C}$ or $60^{\circ} \mathrm{C}$ with $40 \mathrm{~mol} \% \mathrm{PhB}(\mathrm{OH})_{2}$ and 40 mol\% 3- $\mathrm{NH}_{2} \mathrm{C}_{6} \mathrm{H}_{4} \mathrm{~B}(\mathrm{OH})_{2}$ as a catalyst showed similar trend with previous optimization at room temperature (detail sees STable 2 in supporting information).

Because all yields of deoxyfructosazine were measured by crude ${ }^{1} \mathrm{H}$ NMR without internal standard, another two repeated reactions were carried out and their crude products were measured with pyrazine as internal standard for comparison. We repeated reactions in entry 7 as shown (with phenylboronic acid) and entry 8 (with 3-aminophenylboronic acid) in Table 3 (the detail sees quantitative ${ }^{1} \mathrm{H}$ NMR Spectra in experimental section). The recalculated yield of repeated reaction in entry 7 with internal reagent was 74\% (Y: 78\% without internal reagent); the recalculated reaction yield of repeated reaction in entry 8 with internal reagent was $90 \%$ (Y: $84 \%$ without internal reagent). The little difference between yield measured w/o internal standard and that with internal standard for these two cases indicated the data obtained in the absence of internal standard is acceptable in accuracy for this particular condensation reaction. The excellent yields obtained under optimized conditions indicated this catalytic condensation in the presence of arylboronic acids are very promising for upgrade of D-glucosamine hydrogen chloride to value-added product deoxyfructosazine.

Table 3. Optimization on Reaction Temperature.

2

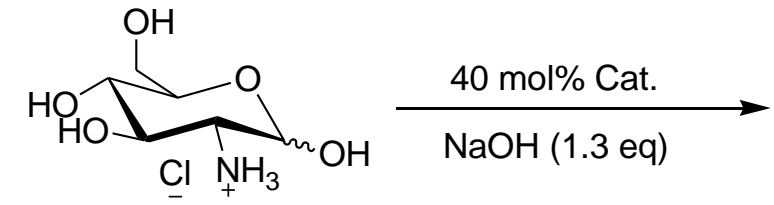

D-Glucosamine hydrogen chloride<smiles>OC[C@@H](O)[C@@H](O)Cc1cnc([C@H](O)[C@H](O)CO)cn1</smiles>

Deoxyfructosazine

\begin{tabular}{|c|c|c|c|c|}
\hline Entry & $\begin{array}{l}\text { Cat. } \\
{\left[\mathrm{ArB}(\mathrm{OH})_{2}\right]}\end{array}$ & Temperature & $\begin{array}{l}\text { Time } \\
\text { (h) }\end{array}$ & Yield $^{[\mathrm{a}]}$ \\
\hline 1 & Phenyl & $40^{\circ} \mathrm{C}$ & 6 & 62 \\
\hline 2 & $3-\mathrm{NH}_{2} \mathrm{C}_{6} \mathrm{H}_{4}$ & $40^{\circ} \mathrm{C}$ & 6 & 69 \\
\hline 3 & 4-Pyridyl & $40^{\circ} \mathrm{C}$ & 6 & 74 \\
\hline 4 & Phenyl & $40^{\circ} \mathrm{C}$ & 12 & 69 \\
\hline 5 & $3-\mathrm{NH}_{2} \mathrm{C}_{6} \mathrm{H}_{4}$ & $40^{\circ} \mathrm{C}$ & 12 & 70 \\
\hline 6 & 4-Pyridyl & $40^{\circ} \mathrm{C}$ & 12 & 78 \\
\hline 7 & Phenyl & $60^{\circ} \mathrm{C}$ & 6 & 85 \\
\hline 8 & $3-\mathrm{NH}_{2} \mathrm{C}_{6} \mathrm{H}_{4}$ & $60^{\circ} \mathrm{C}$ & 6 & 86 \\
\hline 9 & 4-Pyridyl & $60^{\circ} \mathrm{C}$ & 6 & 89 \\
\hline
\end{tabular}

[a] Determined by crude ${ }^{1} \mathrm{H}$ NMR

Global glucosamine market (mainly D-glucosamine hydrogen chloride and D-glucosamine sulfate) was valued at 242.1 million USD in $2020^{27}$, largely driven by supplement industry. Not surprisingly D-glucosamine hydrogen chloride was priced at only $131 \mathrm{USD}$ for $500 \mathrm{~g}$ from TCI Chemicals (Aug. 23, 2021), meanwhile deoxyfructosazine was priced at 1695 USD for 50 mg (Aug. 23, 2021) from Toronto Research Chemicals. The huge price gap makes this arylboronic acids catalysis in water for upgrade of D-glucosamine for deoxyfructosazine very attractive. Although no online data is available for annul market size of deoxyfructosazine, we 
estimated current market should be small from a fact that most of deoxyfructosazine was marketed at mg package online; however, the market is promising to grow quickly in the future regarding deoxyfructosazine's strong potential as a drug precursor and a raw material for speciality chemicals/smart functional materials (Scheme 1).

\section{Reaction mechanism}

Although boron acid-diol complexation ${ }^{28,29}$ and arylboronic acid-monosaccharides ${ }^{30,31}$ was extensively investigated in several recent reports, D-glucosamine was rarely included for these study and experimental data on complex of D-glucosamine-arylboronic acid was not yet known to our best of knowledge. Mechanistic understanding on how arylboronic acid interacts with D-glucosamine and subsequent interacts with condensation product deoxyfructosazine as well as dissociation/tranfer from deoxyfructosazine would be of much important to future design of more efficient arylboronic acid catalystic system.

For condensation pathway, It was proposed that an intermolecular nucleophilic cyclization of D-glucosamine in the presence of catalyst/promoter generates a dihydrofructosazine [2,5bis(d-arabino-tetrahydroxybutyl)dihydropyrazine] intermediate via a dehydration process ${ }^{13,14}$, and this intermediate was detected via mass spectrometry analysis ${ }^{10,32}$ and ${ }^{13} \mathrm{C} \mathrm{NMR}^{32}$. A subsequent dehydration and isomerization formed final product deoxyfructosazine. This pathway was initially proposed when deoxyfrutosazine was discovered ${ }^{10}$ and was widely accepted as a consensus. All reported mechanistic study focused on boric acid, but it is well known that arylboronic acids and boric acid were very different on interaction of monosaccharides $^{33}$. Regarding mechanistic understanding on the role of arylboronic acids catalysts in each step of condensation pathway is not yet studied, here some insights were achieved mostly from ${ }^{1} \mathrm{H}$ NMR study.

\section{$\mathrm{NaCl}$ effect}

Most of commercial D-glucosamine is available in salt form and D-glucosamine hydrogen chloride was usually used for self-condensation in the presence of $\mathrm{NaOH}$ in water; and it means 1 equivalent $\mathrm{NaCl}$ would be in-situ generated in aqueous solution. Our recent study on ${ }^{1} \mathrm{H} \mathrm{NMR}$ elucidation of sugar-NaCl-water complexes ${ }^{34}$ indicated both sodium cation and chloride anion played important role in perturbing hydrogen bonding network of monosaccharides and bulk water. In this study we also observed clear shifts on crude ${ }^{1} \mathrm{H}$ NMR spectra (page 14, supporting information) from control reaction with only D-glucosamine hydrogen chloride (page 6, supporting information) in $\mathrm{NaOH}$ solution (Entry 1, Table 2). Meanwhile a much bigger peak at $\delta 4.96$ (proton of anomer position for beta-form) was observed proved that both $\mathrm{NaCl}$ and $\mathrm{NaOH}$ promoted anomerization of alpha-form to beta-form.

\section{Interaction of arylboronic acid and D-glucosamine}

${ }^{1} \mathrm{H}$ NMR tracking reaction at $40^{\circ} \mathrm{C}$ with phenylboronic acid or $3-\mathrm{NH}_{2} \mathrm{C}_{6} \mathrm{H}_{4} \mathrm{~B}(\mathrm{OH})_{2}$ or 4Pyridy $\mathrm{lB}(\mathrm{OH})_{2}$ as a catalyst $(40 \mathrm{~mol} \%$ ) respectively at $30 \mathrm{mins}, 3 \mathrm{hrs}$ and $12 \mathrm{hrs}$ as well as 30 mins after acidification was performed in order to get some clues on arylboronic acidglucosamine complex (Spectra see 5.0 in supporting information). An obvious decrease on proton peak at anomer position of alpha-D-glucosamine was observed after 30 mins for three parrel reactions; meanwhile an obvious increase on proton peak at the same position after acidification. It suggested that proton at anomer position of alpha-form along with adjacent $\mathrm{NH}_{2}$ group likely participated 1,2-cis-boronated ester bonding with one molecule of arylboronic acid; and such similar bonding at 1,2-cis position was determined in crystal of $(\mathrm{PhB})_{2}\left(\beta-\mathrm{D}-\mathrm{ArapH}_{4}\right)^{35}$ prepared with $\mathrm{D}$-arabinose in the presence of two equivalents of phenylboronic acid. Very recently a 1:1 chelated chelated boron complex of alpha-Dglucosamine and boric acid at 1,2-cis position was also detected in $d_{6}$-DMSO via ${ }^{1} \mathrm{H} /{ }^{13} \mathrm{C}$ 
NMR ${ }^{36}$ However, co-existence of alpha-anomer chelated boronic ester at 3,4-cis position was also highly possible although concentration might be much lower that of 1,2-cis chelated one due to stability difference. Interaction of arylboronic acid and beta-D-glucosamine was not observable in our ${ }^{1} \mathrm{H}$ NMR tracking reactions due to proton at anomer position overlapped with big water peak, a chelation at 3,4-cis position is more probably because two cis-hydroxyls are more favorable to form ester bonds $\mathrm{s}^{30,35}$ with phenylboronic acid.

Interaction of arylboronic acid and deoxyfructosazine

Although three types of borate esters (1,2-bidentate, tridentate and 1,2-bidentate with interaction to nitrogen) were detected in solution of disodium tetraborate (excess)/glucosamine hydrogen chloride via ${ }^{11} \mathrm{~B} /{ }^{13} \mathrm{C}$ NMR spectroscopy ${ }^{13}$ in reported literature, in our study majority of deoxyfructosazine was in free form and only small portion of deoxyfrutosazine chelated with arylboronic acids based on crude ${ }^{1} \mathrm{H}$ NMR after $12 \mathrm{hrs}$ before acidification (Figure 1) (5.0 in supporting information). There are three possible reasons for the observed difference: 1) only $40 \mathrm{~mol} \%$ arylboronic acid was used in our systems meanwhile excess amount of disodium tetraborate was used in reported system; 2) arylboronic acids has less affinity compared to boric acid in chelation with monosaccharides according to results from known study; ${ }^{30} 3$ ) coordination of either arylboronic acids or boric acid with monosaccharides are very dependable on $\mathrm{pH}$ value of aqueous solution. ${ }^{31,33}$

\section{Active arylboronic species}

It is well known that arylboronic acids could switch from free acid form into their boronates form under basic condition, and the latter forms might also act as catalysts. In order to figure out which forms were the real active catalytic species, $\mathrm{pH}$ values were measured with $\mathrm{pH}$ meters for reaction media at 30 mins, after 3 hours and after 12 hours respectively when the reactions were stopped in the parallel reactions under $40^{\circ} \mathrm{C}$ (Entries $4-6$, Table 3). pH Values ranging at $8.35-8.21$ at 30 mins, values ranging at $8.07-8.00$ at 3 hours and values ranging at $8.06-7.97$ at 12 hours were obtained, and the results indicated reactions proceeded in neutral-alkaline solution (Scheme 3). According to pioneering mechanistic study between arylboronic acids and diols in aqueous solution by $\mathrm{K}$. Ishihara ${ }^{37}$, in neutral-alkaline solution order of kinetic reactivities of free boronic acid and its' hydroxyl form is $\operatorname{ArylB}(\mathrm{OH})_{2}>\mathrm{ArylB}^{-}$ $(\mathrm{OH})_{3}$ (sometimes $\left.\operatorname{ArylB}(\mathrm{OH})_{2}>>\operatorname{ArylB}^{-}(\mathrm{OH})_{3}\right)$. Hence arylboronic acids instead of their boronates were proposed as active catalytic species in glucosamine self-condensation although an equilibrated mixture of both forms existed dynamically in the aqueous solutions. The amount of $\mathrm{NaOH}$ in solution was crucial to enable occurrence of a catalytic cycle and overuse of $\mathrm{NaOH}$ could lead to formation of fructosazine byproduct.

Scheme 3. Active arylboronic species.

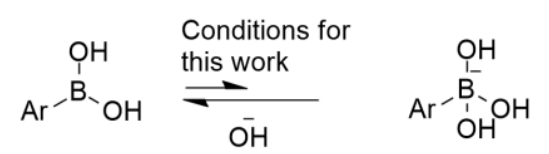

Reaction after 30 mins at $40^{\circ} \mathrm{C} ; \mathrm{pH}=8.35-8.21$

Reaction after 3 hrs at $40^{\circ} \mathrm{C} ; \mathrm{pH}=8.07-8.00$

Reaction after $12 \mathrm{hrs}$ at $40^{\circ} \mathrm{C} ; \mathrm{pH}=8.06-7.97$

Scheme 4. Proposed boron transfer mechanism. 

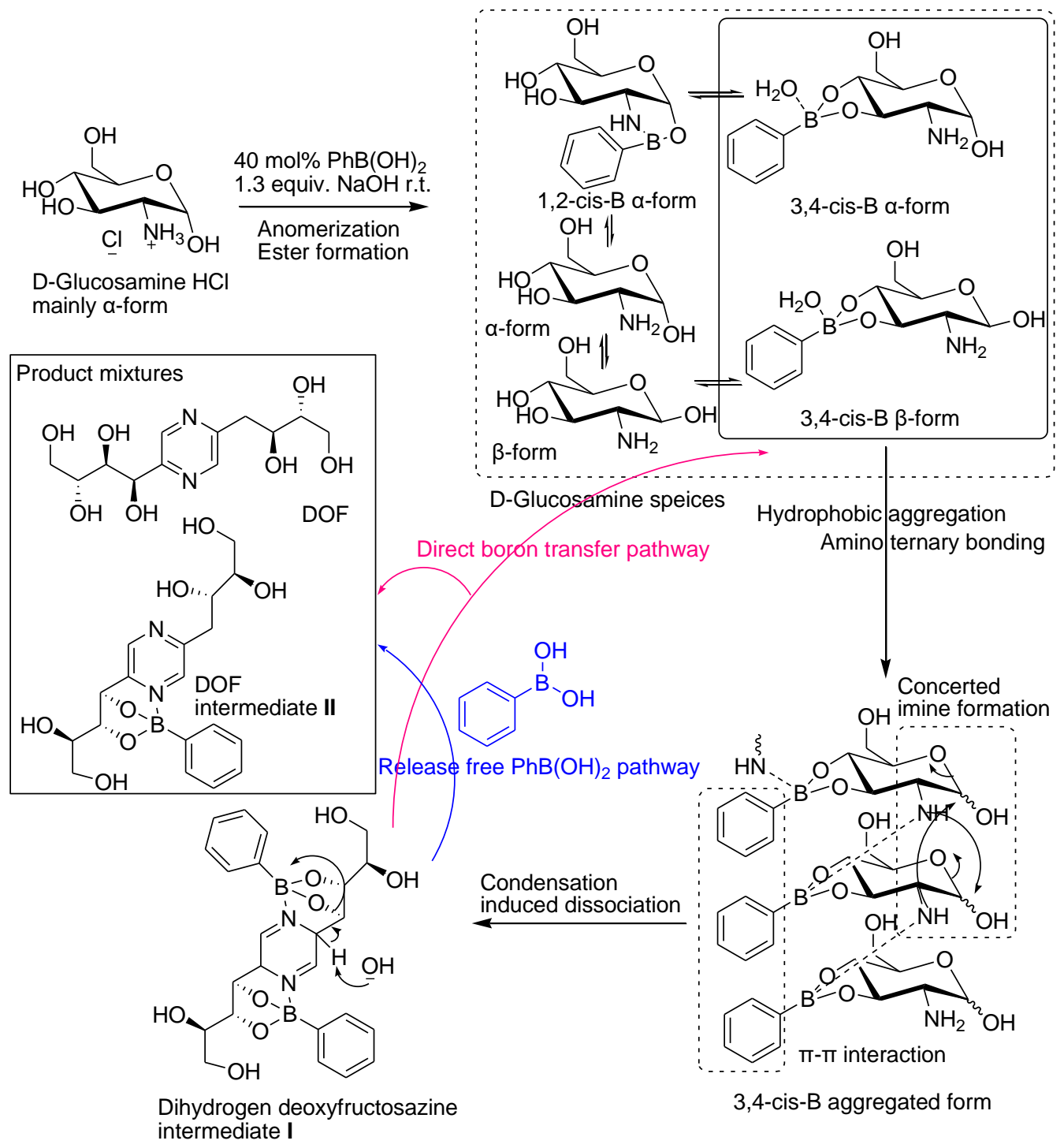

3,4-cis-B aggregated form

\section{Proposed boron transfer mechanism}

With clues in hand, here we proposed an arylboronic acid catalysis mechanism (Scheme 4) in which $\mathrm{pH}$ enabled boron transfer is a key for a catalytic cycle. Initially moderate watersoluble arylboronic acid (solubility in water: $10 \mathrm{~g} / \mathrm{L}, 20^{\circ} \mathrm{C}$ ) reacted with highly hydrated Dglucosamine ${ }^{34}$ forming three types of arylborate esters (1,2-cis chelated alpha-form, 3,4-cis chelated alpha-form and 3,4-cis chelated beta-form), in which anomerization of alpha-form to beta-form promoted mainly by $\mathrm{NaCl}$ and $\mathrm{NaOH}$ (arylboronic acid may also participate in promotion) occurred simultaneously. 1,2-cis chelated alpha-form was very stable and as a rest intermediate it was likely not involved in the condensation as depicted in literature ${ }^{38}$. These newly generated arylborate esters would become amphiphilic because of hydrophobic nature of aryl moieties, and they tend to aggregate due to hydrophobic effect and potential aromatic $\pi-\pi$ interaction; ternary complexes might likely also form via intermolecular of amino functional group of glucosamine and such intermolecular coordination was known in literature ${ }^{39}$. Such hydrophobic aggregation might explain the accelerated rate of condensation in aqueous solution by arylboronic acid. In addition, the amino group or pyridine group of arylboronic acid moiety may also contribute to aggregation via intermolecular hydrogen bonding, lowering energy barrier. It might explain why with $3-\mathrm{NH}_{2} \mathrm{C}_{6} \mathrm{H} 4 \mathrm{~B}(\mathrm{OH})_{2}$ or 4pyridylB $(\mathrm{OH})_{2}$ yield of deoxyfructosazine was remarkable higher at room temperature than that with any of other aryboronic acids; while the difference became much narrow when 
temperature was increased to $60^{\circ} \mathrm{C}$ (hydrogen bonding would be much weaker at high temperature). Such closer complexes would likely lead to imine condensation of two adjacent glucosamine moieties (they could be both alpha-forms or both beta-forms or a mixture) likely in a concerted manner because aldehyde peak from acyclic form of glucosamine was never observed in all ${ }^{1} \mathrm{H}$ NMR tracking reactions (5.0 in supporting information); however, we cannot rule out the possibility on reactions occurred in acyclic form ${ }^{13,30}$ because open forms of monosaccharides were much more reactive even though in very low concentration. Then the newly generated six-membered ring of dihydrofructosazine [2,5-bis(d-arabinotetrahydroxybutyl)dihydropyrazine] intermediate I may break the two arylborate esters from aggregated complexes because of steric effect. A subsequent chem-selective dehydration directed by arylboronic ester ${ }^{40}$ occurred and this arylboronic acid may dissociate to be a free acid form or transfer to D-glucosamine raw material regenerating a glucosamine arylborate ester; then a followed isomerization generated arylboronic acid protected deoxyfructosazine intermediate II. Because of better water-soluble pyrazine moiety and seven hydroxyls, arylboronic acid protected deoxyfructosazine would have a stronger hydrate effect in water and tend to stay in bulk water; that could favor equilibration to an arylborate ester via direct boron transfer or dissociation to a free arylboronic acid followed with a chelation to glucosamine, completing a catalytic cycle. The existence of arylboronic acid is a key to push dihydrofructosazine intermediate to dehydration ${ }^{40}$ (to deoxyfructosazine) rather than dehydrogenation (to fructosazine).

\section{Conclusion}

In summary, we developed an arylboronic acids catalyzed upgrade from D-glucosamine hydrogen chloride for DOF in aqueous media. DOF is proposed to be a promising bio-based platform molecule for new drug lead and design of speciality chemicals/functional materials in the future because of its unique structure containing pyrazine moiety and multiple hydroxyls. Regarding broad use of high-end speciality chemicals/functional materials, we envisage that this catalysis development could accelerate utilization of chitin via organic solvent free upgrade of its most commercially available monomer (D-glucosamine). Due to current difficulty and relatively high cost in hydrolysis of chitin and subsequent purification process, the price of Dglucosamine is still too high as a renewable nitrogen source to prepare most of amine raw materials in chemical industry; this proposed integration of DOF with renewable nitrogen into high-end speciality chemicals/functional materials looks more practical in the near future toward decarbonation in chemical industry.

Mechanistic study including $\mathrm{NaCl}$ effect, interaction of arylboronic acid with Dglucosamines, intermediates and DOF was also investigated for the first time. The hydrophobic aggregation promoted by boronic acids might explain the accelerated condensation rate and a $\mathrm{pH}$ enabled boron transfer via direct transfer or dissociation was a key for the catalysis cycle. Such new insights might be of much important for further improvement of this condensation process and design of new arylboronic acid for catalyzing selective monosaccharides transformations in aqueous media.

\section{Supporting Information}

The Supporting Information is available free of charge on this website.

\section{AUTHOR INFORMATION}

\section{Corresponding Author}

* Yiqun Li E-mail: tlyq@jnu.edu.cn

*Liuqun Gu E-mail: guliuqun@yahoo.com 


\section{Author Contributions}

L. Gu designed concept; M. Wang and G. Zhu carried out all experiments as well as collected all experimental data; both L.Gu and Y. Li supervised this project; L. Gu analyzed the data and drafted manuscript; All authors edited manuscript and had given approval to the final version of the manuscript.

\section{ACKNOWLEDGMENT}

We acknowledge a startup funding from Jinan University to L. Gu (No: 88015155 and 88016607) and funding of the National Natural Science Foundation of China (No. 21372099) to Y. Li.

\section{Reference}

[1] Froidevaux, V.; Negrell, C.; Caillol, S.; Pascault, J.-P. and Boutevin, B. Biobased Amines: From Synthesis to Polymers; Present and Future Chem. Rev. 2016, 116, 14181-14224.

[2] Shi, X.; Ye, X.; Zhong, H.; Wang, T.; Jin, F. Sustainable nitrogen-containing chemicals and materials from natural marine resources chitin and microalgae. Mol. 2021, 505, 111517.

[3] Joseph, S. M.; Krishnamoorthy, S.; Paranthaman, R.; Moses, J. A.; Anandharamakrishnan C. A review on source-specific chemistry, functionality, and applications of chitin and chitosan. Carbohydrate Polymer Technologies and Applications 2021, 2, 100036.

[4] Peter, S.; Lyczko, N.; Gopakumar, D.; Maria, H. J.; Nzihou, A.; Thomas S. Chitin and Chitosan Based Composites for Energy and Environmental Applications: A Review. Waste and Biomass Valorization 2021, 12, 4777-4804.

[5] Berezina, N. Production and application of chitin. Phys. Sci. Rev. 2016, 20160048.

[6] Chen, X.; Yang, H.; and Yan, N. Shell Biorefinery: Dream or Reality? Chem. Eur. J. 2016, 22, 13402-13421.

[7] Xie, S.; Jia, C.; Ong, S. S. G.; Wang, Z.; Zhu, M.; Wang, Q.; Yang, Y.; and Lin H. A Shortcut Route to Close Nitrogen Cycle: Bio-Based Amines Production via Selective Deoxygenation of Chitin Monomers over Ru/C in Acidic Solutions. iScience 2020, 23, 101096.

[8] Evers, M. Association of deoxyfructosazine and an antidiabetic of the biguanide family WIPO (PCT) patent: wo2001047522A3, 2002.

[9] Zhu, A.; Huang, J.; Clark, A.; Romero, R.; Petty, H. R. 2,5-Deoxyfructosazine, a D-glucosamine derivative, inhibits T-cell interleukin-2 production better than d-glucosamine. Carbohydr. Res., 2007, 342, 2745-2749.

[10] Sumoto, K.; Irie, M.; Mibu, N.; Miyano, S.; Nakashima, Y.; Watanabe, K.; Yamaguchi, T. Formation of Pyrazine Derivatives from D-glucosamine and Their Deoxyribonucleic acid (DNA) Strand Breakage Activity. Chem. Pharm. Bull., 1991, 39, 792.

[11] Scutelnic, V.; Tsuru, S.; Pápai, M.; Yang, Z.; Epshtein, M.; Xue, T.; Haugen, E.; Kobayashi, Y.; Krylov, A. I.; Møller, K. B.; Coriani, S. \& Leone, S. R. X-ray transient absorption reveals the Au ( $\left.n \pi^{*}\right)$ state of pyrazine in electronic relaxation. Nat. Commun. 2021, 12, 5003.

[12] H. Sardon, D. Mecerreyes, A. Basterretxea, L. Avérous, and C. Jehanno From Lab to Market: Current Strategies for the Production of Biobased Polyols. ACS Sustainable Chemistry \& Engineering 2021 9, $10664-$ 10677.

[13] Rohovec, J.; Kotek, J.; Peters, J. A. and Maschmeyer, T. A Clean Conversion of D-Glucosamine Hydrochloride to a Pyrazine in the Presence of Phenylboronate or Borate. Eur. J. Org. Chem., 2001, 3899-3901. 
[14] Kuhn, R.; Kruger, G.; Haas, H. J.; Seeliger, A. Aminozucker-Synthesen, XXIV. Pyrazinbildung aus Aminozuckern. Justus Liebigs Ann. Chem., 1961, 644, 122-127.

[15] Pan, H. Recent Progress in Organic Transformations Catalyzed by Organoboronic Acids. China Petroleum and Chemical Standard and Quality, 2013, 12, 34, in Chinese.

[16] Jia, L.; Zhang, Z.; Qiao, Y.; Pedersen, C. M.; Ge, H.; Wei, Z.; Deng, T.; Ren, J.; Liu, X.; Wang, Y. and Hou, X Product Distribution Control for Glucosamine Condensation: Nuclear Magnetic Resonance (NMR) Investigation Substantiated by Density Functional Calculations. Ind. Eng. Chem. Res., 2017, 56, 2925-2934.

[17] Wu, M.; Ma, H.; Ma, Z.; Jin, Y.; Chen, C.; Guo, X.; Qiao, Y.; Pedersen, C. M.; Hou, X. and Wang, Y. Deep Eutectic Solvents: Green Solvents and Catalysts for the Preparation of Pyrazine Derivatives by SelfCondensation of d-Glucosamine. ACS Sustainable Chemistry \& Engineering 2018, 6, 9434-9441.

[18] Boronic Acids-Preparation and Applications in Organic Synthesis Medicine and Materials (Ed.: D. G. Hall), 2nd Ed., Wiley-VCH, Weinheim, 2011.

[19] Zheng, H.; Ghanbari, S.; Nakamura, S. and Hall, D. G. Boronic Acid Catalysis as a Mild and Versatile Strategy for Direct Carbo- and Heterocyclizations of Free Allylic Alcohols. Angew. Chem. Int. Ed. 2012, 51, 61876190.

[20] Boronic Acid-catalyzed Reactions of Carboxylic Acids (K. Ishihara), part of "Synthesis and Application of Organoboron Compounds" (Ed: E. Fernandez, A. Whiting), Springer, 2015, pp243-270.

[21] Nishi, N.; Nashida, J.; Kaji, E.; Takahashi, D.; Toshima, K. Regio- and Stereoselective $\beta$-Mannosylation using a Boronic Acid Catalyst and Its Application in the Synthesis of a Tetrasaccharide Repeating Unit of Lipopolysaccharide Derived from E. coli 075. Chem. Commun., 2017, 53, 3018-3021.

[22] Tanaka, M.; Nakagawa, A.; Nishi, N.; lijima, K.; Sawa, R.; Takahashi, D.; Toshima, K. Boronic-Acid-Catalyzed Regioselective and 1,2-cis-Stereoselective Glycosylation of Unprotected Sugar Acceptors via SNi-Type Mechanism. J. Am. Chem. Soc. 2018, 140, 3644-3651.

[23] Kuwano, S.; Hosaka, Y. and Arai, T. Chiral Benzazaborole-Catalyzed Regioselective Sulfonylation of Unprotected Carbohydrate Derivatives Chem. Eur. J. 2019, 25, 12920-12923.

[24] Dailler, D.; Dorst, A.; Schäfle, D.; Sanderet, P.\& Gademannal, K. Novel fidaxomicin antibiotics through site-selective catalysis. Commun Chem. 2021, 4, 59.

[25] Gu, L.; Lim, J.; Cheong, J. L. and Lee, S. S. MCF-supported Boronic Acids as Efficient Catalysts for Direct AmideCondensation of Carboxylic Acids and Amines. Chem. Commun. 2014, 50, 7017-7019.

[26] The solvent peak between $1.0 \mathrm{ppm}$ to $1.25 \mathrm{ppm}$ belonged to residual ethanol because ethanol was added for fast evaporation of water solvent after acidification of completed reactions (detail see supporting information).

[27] Data from www.ktvn.com: Glucosamine Market Size is Estimated to Grow with a CAGR of 1.5\% - KTVN Channel 2 - Reno Tahoe Sparks News, Weather, Video.

[28] Springsteen, G. and Wang, B. A Detailed Examination of Boronic acid-diol Complexation. Tetrahedron, 2002, 58, 5291-5300.

[29] Ni, N.; Laughlin, S.; Wang, Y.; Feng, Y.; Zheng, Y.; Wang, B. Probing the General Time Scale Question of Boronic Acid Binding with Sugars in Aqueous Solution at Physiological pH. Bioorg. Med. Chem., 2012, $20,2957-$ 2961.

[30] Peters, J. A. Interactions between boric acid derivatives and saccharides in aqueous media: Structures and stabilities of resulting esters Coord. Chem. Rev. 2014, 268, 1-22.

[31] Kurogochi, M.Mizuno, M. Matsuda, A. Binding Assessment of Monosaccharide-Boronic Acid Complexes via Tandem Mass Spectrometry. ChemistrySelect 2018, 3, 8193-8198. 
[32] Jia, L.; Liu, X.; Qiao, Y.; Pedersen, C. M.; Zhang, Z.; Ge, H.; Wei, Z.; Chen, Y.; Wen, X.; Hou, X.; Wang, Y. Mechanism of the self-condensation of GIcNH2: insights from in situ NMR spectroscopy and DFT study, Applied Catalysis B: Environmental 2017, 202, 420-429.

[33] Barker, S. A.; Chopra, A. K.; Hatt, B. W. and Somers, P. J. The interaction of areneboronic acids with monosaccharides. Carbohydr. Res. 1973, 26, 33-40.

[34] Zhu, G.; Li, H.; Li, Y.; Gu, L. "NMR Elucidation of Observed Stable Sugar-NaCl-water Complexes in Aqueous Solution" preprint at ChemRxiv (2021). Link: 10.33774/chemrxiv-2021-t8k0j-v2. (Submitted and under review). [35] Reichvilser, M. M.; Heinzl, C.; Klüfers, P. Boronic acid mono- and diesters of the aldopentoses, Carbohydr. Res., 2010, 345, 498-502.

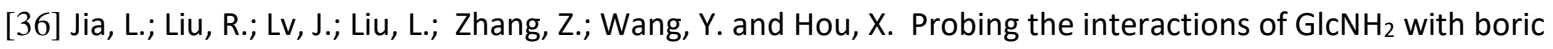
acid via NMR spectroscopy. Phys. Chem. Chem. Phys., 2021, 23, 15758-15765.

[37] Furikado, Y.; Nagahata, T.; Okamoto, T.; Sugaya, T.; Iwatsuki, S.; Inamo, M.; Takagi, H. D.; Odani, A.; Ishihara, K. Universal Reaction Mechanism of Boronic Acids with Diols in Aqueous Solution: Kinetics and the Basic Concept of a Conditional Formation Constant. Chem. Eur. J., 2014, 20, 13194-13202.

[38] Khokhlova, E.A.; Kachala, V. V.; Ananikov, V. P. The first molecular level monitoring of carbohydrate conversion to 5-hydroxymethylfurfural in ionic liquids. $\mathrm{B}_{2} \mathrm{O}_{3}$--an efficient dual-function metal-free promoter for environmentally benign applications. ChemSusChem, 2012, 5, 783-789.

[39] Bosch, L. I.; Fyles, T. M.; James, T. D. Binary and ternary phenylboronic acid complexes with saccharides and Lewis bases. Tetrahedron, 2004, 60, 11175-11190.

[40] Istasse, T.; Lemaur, V.; Debroux, G.; Bockstal, L.; Lazzaroni, R.; Richel, A. Monosaccharides Dehydration Assisted by Formation of Borate Esters of $\alpha$-Hydroxyacids in Choline Chloride-Based Low Melting Mixtures.

Front. Chem., 2020, 8: 569. 